\title{
The M015 Cell Cycle Kinase Is Associated with the TFIIH Transcription-DNA Repair Factor
}

\author{
Richard Roy, "† Jörg P. Adamczewski, "† \\ Thierry Seroz, * Wim Vermeulen, \\ Jean-Pierre Tassan, \$ Laurent Schaeffer, ${ }^{*}$ \\ Erich A. Nigg, $\$$ Jan $H_{*}$ J. Hoeijmakers, \\ and Jean-Marc Egly* \\ *Institut de Génétique et de Biologie Moléculaire \\ et Celluiaire \\ Centre National de la Recherche Scientifique \\ Institut National de la Santé et de la Recherche \\ Médicale \\ 1, rue Laurent Fries \\ 67404 llikirch Cédex \\ France \\ fDepartment of Cell Biology and Genetics \\ Medical Genetics Center \\ Erasmus University Rotterdam \\ 3000 DR Rotterdam \\ The Netherlands \\ $\$$ Swiss Institute for Experimental Cancer Research \\ 155 Chemin des Boveresses \\ 1066 Epalinges \\ Switzerland
}

\section{Summary}

A protein kinase activity that phosphorylates the C-terminal domain (CTD) of RNA polymerase II and is associated with the basal transcription-repair factor TFIIH (also called BTF2) resides with M015, a cyclin-dependent protein kinase that was first found to be involved in cell cycle regulation. Using in vivo and in vitro repair assays, we show that M015 is important for nucleotide excision repair, most likely through its association with TFIIH, thus providing an unexpected link among three important cellular mechanisms.

\section{Introduction}

The initiation of protein-coding gene transcription requires the assembly of a complex including the basal transcription factors and RNA polymerase II (RNA pol II) at the promoter (reviewed by Chalut et al., 1994). One of these factors, TFliH (also called BTF2), like its rat and yeast counterparts (Conaway and Conaway, 1989; Feaver et al., 1991), possesses DNA-dependent ATPase, helicase, and protein kinase activities that may be involved in both transcription initiation (Serizawa et al., 1993; Roy et al., 1994) and in nucleotide excision repair (NER) (Feaver et al., 1993; Schaeffer et al., 1993, 1994; Drapkin et al., 1994; Wang et al., 1994). The DNA-dependent ATPase probably reflects the helicase activities of p89 (XPB/ERCC3) and

TThe first wo authors contributed equally to this work p80 (XPD/ERCC2) that may be involved in unwinding DNA in both transcription (Wang et al., 1992) and repair (Ma et al., 1994). Although their exact role remains elusive, mutations in these two (and in an uncharacterized third TFIIH subunit) are responsible for three severe human syndromes: the cancer-prone repair disorder xeroderma pigmentosum (XP groups $B$ and D) and the neurodevelopmental conditions Cockayne's syndrome and trichothiodystrophy (reviewed by Bootsma and Hoelimakers, 1993). Many clinical features associated with the latter two disorders may in fact be due to a subtle defect in the basal transcription function of TFIIH, and, as such, they may uncover the manifestations of a previously unrecognized transcription syndrome.

The protein kinase activity of TFIIH has been shown to phosphorylate the C-terminal domain (CTD) of the large subunit of RNA pol II (Lu et al., 1992), a modification that occurs prior to elongation (reviewed by Dahmus, 1994). The nonphosphorylated form interacts preferentially with the TATA-binding protein (TBP) (Usheva et al., 1992), leading to the assumption that the phosphorylation of RNA pol Il could disrupt its interaction with TBP, consequently freeing the elongation complex from its TBP anchor or other basal transcription factors at the promoter.

We now report that the TFIIH-associated CTD kinase activity resides with MO15, which was previously identified as the catalytic subunit of CDK-activating kinase (CAK), a cyclin-dependent protein kinase that phosphorylates $p 34^{c d c 2}$ and $p 33^{c d k 2}$ in an action required for the cell cycle to proceed (Fesquet et al., 1993; Poon et al., 1993; Fisher and Morgan, 1994; Mäkelä et al., 1994; Tassan et al., 1994).

\section{Results}

\section{Identification of M015}

When a partially purified TFIIH fraction was subjected to an immunoaffinity chromatography using an antibody directed against the $62 \mathrm{kDa}$ subunit of $T F I H$, additional polypeptides with molecular masses of $80 \mathrm{kDa}$ (the XPD/ ERCC2 helicase), $38 \mathrm{kDa}$, and $32 \mathrm{kDa}$ were found to copurify with the five previously identified members (Gerrard et al., 1991; Fischer et al., 1992). Amino acid sequence analysis of tryptic peptides derived from the $38 \mathrm{kD}$ a polypeptide gave KLADFGLAK and KLDFLGEGQFATVYK, which corresponded to the $40 \mathrm{kDa}$ cdc2-related protein kinase MO15 (Tassan et al., 1994).

We thus examined the presence of MO15 and the CTD kinase throughout the final stages of the TFIIH purification procedure (Figures 1A-1C), using immunoblots with antiMO15 antibodies (Tassan et al., 1994); using the CTD kinase assay in which a synthetic peptide (ctd4) mimicking four repeats of the CTD of the largest subunit of RNA pol II was used as a substrate; using the phosphorylation of glutathione S-transferase (GST)-cdk2, a known in vitro substrate of Xenopus laevis and human MO15; and using the CAK assay (Poon et al., 1993) wherein MO15 phospho- 
A

Heparin fractions

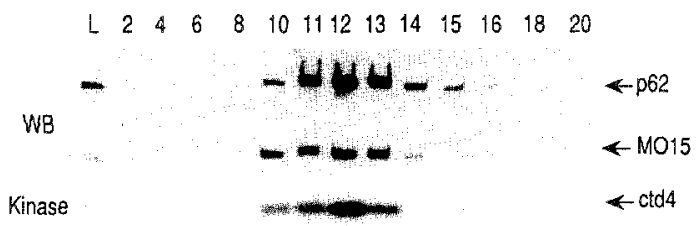

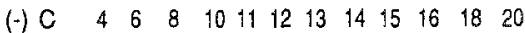

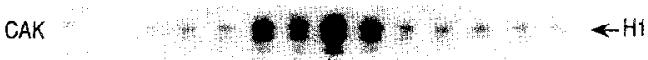

B

FT $2 \begin{array}{llllllllllll}4 & 6 & 8 & 10 & 12 & 14 & 16 & 18 & 20 & 22 & 24 & 26\end{array}$

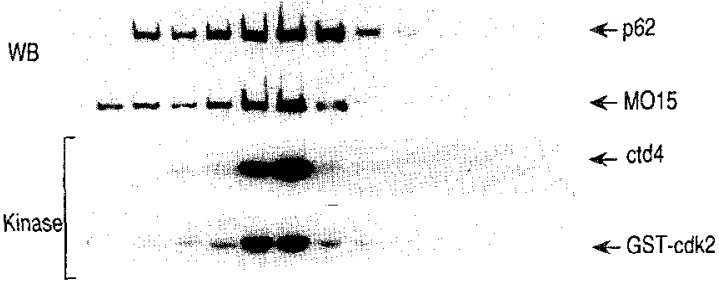

$(-) C 52 \quad 4 \quad 6 \quad 8 \quad 101214 \quad 1618 \quad 20 \quad 22 \quad 24 \quad 26$
C Glycerol gradient fractions $(50 \mathrm{mM} \mathrm{KCl})$

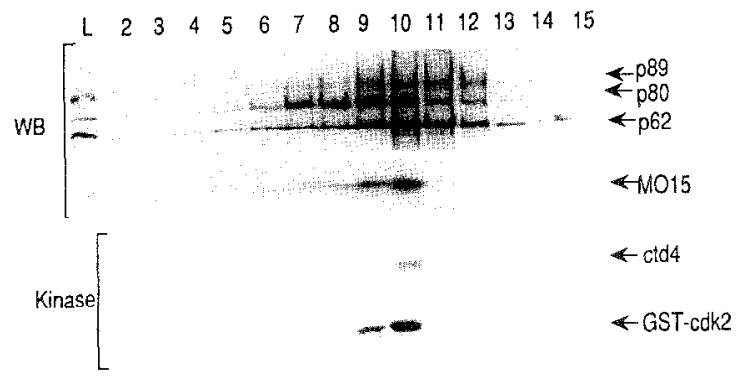

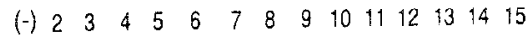

CAK

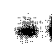

$\leftarrow \mathrm{H} 1$

Figure 1. Copurification of MO15 with TFIIH

A transcriptionally active sulfopropyl fraction was successively separated on a heparin-5PW (A), HAP (B), and a $50 \mathrm{mM} \mathrm{KCl}$ glycerol gradient (C) as previously described (Gérard et al., 1991). Each fraction was analyzed on an $11 \%$ SDS-polyacrylamide gel $(10 \mu \mathrm{l})$ and immunoblotted with antibodies against all of the TFIIH subunits (Ab-ERCC3 for $p 89, A b-E R C C 2$ for $p 80$, and $A b-3 c 9$ for $p 62$ ) and, when indicated, with antibodies against p44, p34, and MO15. Aliquots of the same fractions were subjected to a kinase assay (3-6 $\mu \mathrm{l})$, using ctd4 as a substrate, and to a CAK assay (10-20 $\mu$ ), resulting in phosphorylation of histone $\mathrm{H}$ T. The phosphorylation of $E$. coli overexpressed GSTcdk2 by $10 \mu \mathrm{l}$ of each fraction was also tested (Poon et al., 1993). WB, Western blot; lane L, loading material; as negative control, the CAK assay was performed on buffer (minus) and on peak fractions without addition of GST-cdk2 (C).

rylates and hence activates $p 33^{\text {cok2 }}$ in the presence of cyclin $A$ and subsequently $p 33^{c d k 2}$ phosphorylates histone $\mathrm{H} 1$ in the presence of radioactive $\left[\gamma^{-32} \mathrm{P}\right] \mathrm{ATP}$. On the heparin-5PW and hydroxyapatite (HAP) columns, MO15 (as observed by immunoblotting, cdk2 phosphorylation, and the

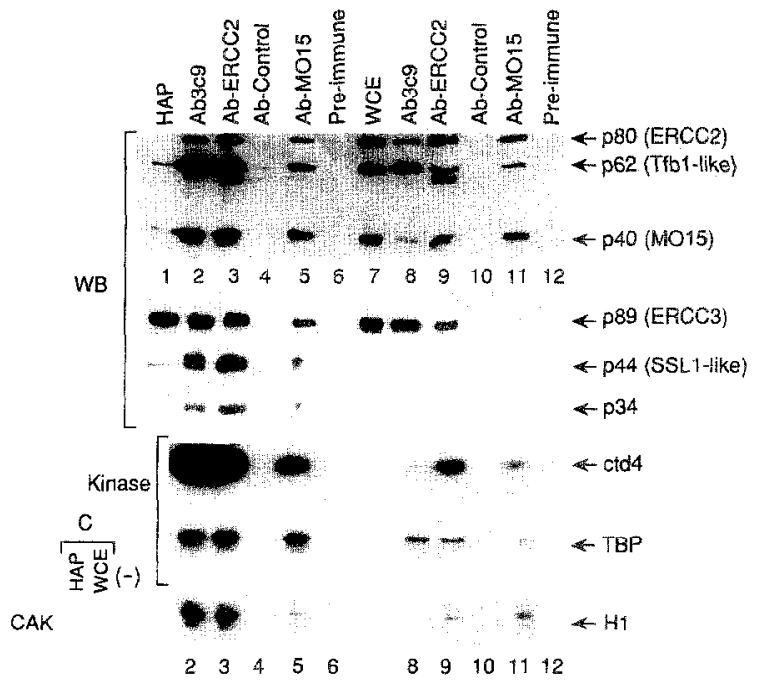

Flgure 2. Coimmunoprecipltation of $\mathrm{TFIIH}$ and $\mathrm{MO} 15$

Protein A-Sepharose beads carrying the Ab-3c9 (lanes 2 and 8 ), ADERCC2 (lanes 3 and 9), and Ab-MO15 (lanes 5 and 11) antibodies and Ab-GST (lanes 4 and 10) or preimmune serum (lanes 6 and 12) were incubated with $50 \mu$ l of highly purified TFIIH (HAP elute) (lanes $1-6$ ) or $200 \mu$ t of WCE (lanes 7-12). After extensive washing, half of the beads were eluted by boiling in SDS sample buffer, analyzed by SDS-PAGE, and immunoblotted using the antibodies described in the legend of Figure 1. The remaining beads were subjected to kinase assays, using either CTD or TBP as substrates, or to CAK assays. The lane marked by the minus shows a negative control; HAP and WCE were tested without adding GST-CdK2 (C). WB, Western blot.

CAK assay) copurifies with p62 and CTD kinase activity (Figure 1A, lanes 10-14; Figure 1B, lanes 8-14). We then loaded the TFIIH (HAP fraction) onto a glycerol gradient $(50 \mathrm{mM} \mathrm{KCl})$. We observed that phosphorylation of ctd4, GST-cdk2, and CAK activity copurifies with MO15 and the three TFIIH subunits peaking in fractions 9 and 10 (Figure 1C).

\section{Characterization of the M015 Polypeptide Complexe(s)}

The copurification experiments strongly suggest, but do not prove, that MO15 is part of the TFIIH complex. To obtain evidence for a physical association between MO15 and other TFIIH components and to characterize the M015-associated polypeptides, we performed parallel immunoprecipitations (Figure 2) from HAP and HeLa wholecell extract (WCE) using $A b-3 c 9, A b-E R C C 2$, and $A b-$ MO15 antibodies against either p62 (Fischer et al., 1992), p80/ERCC2 (Schaeffer et al., 1994), or p40/MO15 (Tassan et al., 1994), respectively. Antibodies directed against the TFIIH subunits $\mathrm{p} 34$ and $\mathrm{p} 44$ were also used where indicated (Humbert et al., 1994).

Qualitatively both sets of immunoprecipitations performed with the HAP and the WCE fractions gave the same result: $\mathrm{Ab}-3 \mathrm{C} 9$, Ab-ERCC2, and Ab-MO15 antibodies im. munoprecipitated all the previously characterized subunits of TFIIH ( $p 89, p 80, p 62, p 44$, and $p 34$ ), in addition to M015. In the two controls, none of these polypeptides was detected.

A quantitative analysis of the polypeptides precipitated 


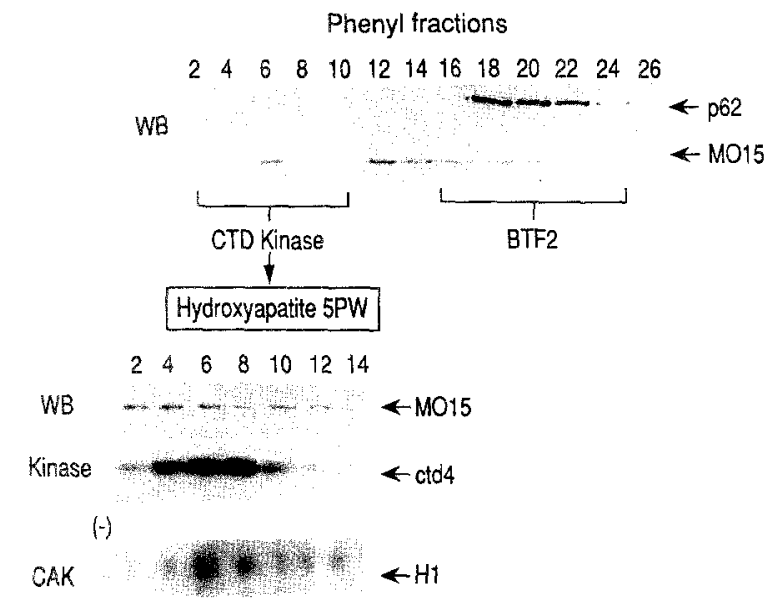

Figure 3. Some MO15 Can Be Resolved from TFIlH

Aliquots $(20 \mu \mathrm{l})$ from the phenyl-5PW fractions $(0.4-0.0 \mathrm{M}$ ammonium sulfate gradient) were analyzed by Western biot (WB) for the presence of MO15 and p62. Fractions 3-10 were applied onto a HAP-5PW column (Gerrard et al., 1991) and tested as described in the legend of Figure 2.

with the three antibodies $\mathrm{Ab}-3 \mathrm{c} 9, \mathrm{Ab}-\mathrm{ERCC} 2$, and $\mathrm{Ab}$ M015, however, shows important differences. The ratios among the six polypeptides immunoprecipitated from HAP are almost identical, independently of the antibody used (compare lanes 2, 3, and 5 in Figure 2), which suggests that all five of the TFIIH subunits and MO15 belong to one homogeneous protein complex. When WCE is used as starting material, the ratios among the various polypeptides vary depending on the antibody employed (Figure 2, lanes 7-12). Ab-3c9 immunoprecipitates much less $p 80$ and MO15 compared with p62, while Ab-ERCC2 and AbMO15 immunoprecipitate $\mathrm{p} 80$ and MO15 in similar proportions but comparatively less p 62 and p 89 (Figure 2, lanes 8,9 , and 11). Furthermore, the ratio of $p 80$ to MO15 is constant regardless of whether an anti-ERCC2 or an antiMO15 antibody is used, implying a direct relationship between these two polypeptides. All together, these results suggest that there are at least two complexes that contain MO15 in the HeLa WCE fraction.

Phosphorylation of the ctd4 synthetic oligopeptide, as well as the CAK activity, is directly proportional to the M015 polypeptide concentration, suggesting that MO15 kinase activity is independent of the polypeptide composition of the immunoprecipitated complexes. When TBP is used as a substrate, we observed a different phosphoryla. tion efficiency that was not proportional to the MO15 polypeptide concentration (compare lane 8 with lane 11 in Figure 2). It was not possible to elute the protein complexes from the immunoadsorbant in nondenaturing conditions to evaluate their transcription activity.

\section{M015 Possesses CTD KInase Activity}

To correlate the presence of MO15 with the CTD kinase activity, an intermediate fraction was separated on a phenyl-5PW column. Elution of TFIIH occurs between 0.25 and $0.10 \mathrm{M}$ ammonium sulfate, corresponding to fractions
Table 1. Comparison of Kinase Activities between MO15 and TFIH

\begin{tabular}{lcc}
\hline Effectors & MO15 $^{\mathrm{a}}$ & TFIH $^{\mathrm{D}}$ \\
\hline ATP & + & + \\
dATP & + & + \\
GTP & + & + \\
CTP & - & - \\
CAMP & - & - \\
YSPTSPS wild type & + & + \\
YAPTSPS mutant & + & + \\
YSPTAPS mutant & - & - \\
RNA pol II (yeast) & + & + \\
rp33cok2 & + & - \\
Histone & - & - \\
Casein & - & + \\
pUC309 & - & -
\end{tabular}

Competition assays using the oligopeptide ctd 4 were performed with MO15 or TFIIH and different nucleotide substrates. Phosphorylation of synthetic peptides corresponding to the CTD consensus sequence (YSPTSPS wild type) or alanine-substituted mutants (1 $\mu \mathrm{g}$ per assay), RNA pol II (yeast) (a gift from J. M. Rivat) (50 ng per assay), recomblnant $E$. coli overexpressed rp33 $3^{\circ \alpha 2}$, and histone $H 1$ and casein (Sigma) ( $1 \mu \mathrm{g}$ per assay each) were tested as substrates in kinase reactions. The effect of pUC309 (100 ng per assay) on the phosphorylation of RNA pol II was as described (Serizawa et al., 1992). Plus designates whether excess radioinert nucleotide $(1 \mathrm{mM})$ could compete the ATP. dependent reaction, whether the polypeptide substrate could be phosphorylated, or whether the presence of promoter-containing DNA stimulated the phosphorylation of RNA pol li.

${ }^{a}$ MO15 was resolved on HAP (see Figure 3) fraction 8 at $3 \mu l(10 \mathrm{ng}$ ) per assay.

- TFIIH was resolved on HAP fraction 12 at $3 \mu l(10$ ng) per assay.

"Synthetic peptide consisting of eight copies of the wild-type or the mutated CTD consensus sequence.

"puC309 is a pUC-derived plasmid that contains the adenovirus 2 major late promoter from regions -677 to +33 .

$16-24$ as judged by the presence of p62, whereas MO15 and CTD kinase activity eluted with a much broader peak (Figure 3, top panel; data not shown). No traces of the characterized TFIIH subunits could be detected in the fractions 2-10. Note also that a portion of the M015 coelutes with TFIIH (fractions 18-22). Fractions 3-10 were then run over a HAP column. MO15, CTD kinase, and CAK activity elute in fractions 4-10 (Figure 3, lower panel).

We then compared the kinase activity of both MO15 (HAP fraction 8; Figure 3) and TFIIH (Gerard et al., 1991). This MO15 fraction contains the MO15 polypeptide and likely its regulatory subunit(s), as evidenced by the observed CAK activity. As summarized in Table 1, the nucleotide specificities of MO15 and TFIIH are identical: ATP, DATP, and GTP all act as colactors for the CTD kinase in competition assays, while CTP or CAMP had no effect on the phosphorylation of ctd4. Both TFIIt and MO15 are similarly inhibited by staurosporin and by the isoquinoline sulfonamide derivative $\mathrm{H}-8$ (data not shown; Serizawa et al, 1993). By using synthetic peptides that correspond to the wild-type CTD consensus sequence (YSPTSPS) or peptides that contain alanine substitutions at serine positions 2 or 5 , we show that TFIIH and MO15 exclusively phosphorylate the serine at position 5 (Table 1), similar to yeast factor b (J. Corden, unpublished data). 
Glycerol gradient fractions

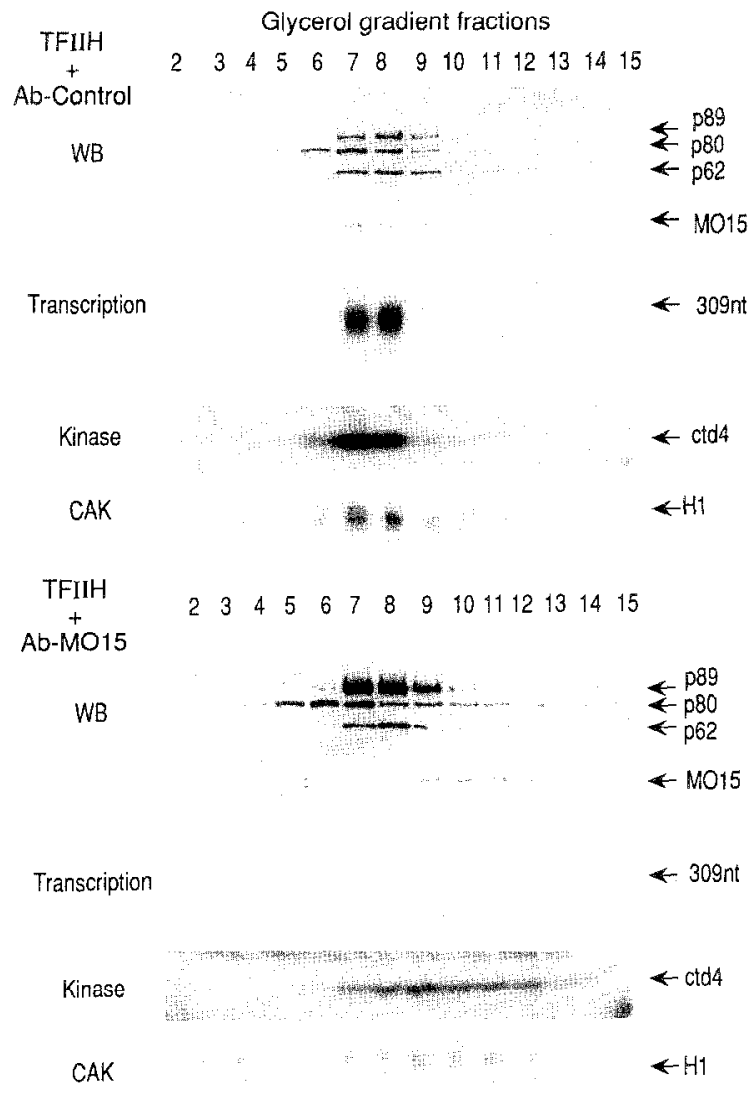

Figure 4. Ab-MO15 Antibody Shifts MO15-Associated Kinase Activities through a Glycerol Gradient

HAP $(200 \mu l)$ (fraction 12) was incubated for $1 \mathrm{hr}$ at $4^{\circ} \mathrm{C}$ with purified rabbit polyclonal antibodies directed against either TFIIB (TFIIH plus Ab-Control) or MO15 (TFIIH plus Ab-MO15) before glycerol gradient centrifugation (Schaeffer et al., 1994). Aliquots $(10 \mu l)$ were tested for TFIIH-dependent transcription, CTD kinase, and CAK actlvity and immunoblotted as in Figure 1. The specific runoff transcript is marked as 309 nt. WB, Western blot.

RNA pol II from yeast was weakly phosphorylated and Escherichia coli overexpressed recombinant $p 33^{c d k 2}$ was strongly phosphorylated in solution, while two common proline-directed kinase substrates, histone $\mathrm{H} 1$ and casein, were not phosphorylated by either of the kinase fractions. Phosphorylation of the CTD of the RNA pol II under transcription conditions was highly stimulated by the presence of promoter DNA (pUC309) only in reactions performed with TFIIH. No such effect was observed with MO15.

Taken together, these data show that MO15 and TFIIH exhibit nearly identical kinase properties, suggesting that the presence of MO15 polypeptide in the TFIIH complex is ultimately responsible for its kinase activity. However, when RNA pol II phosphorylation was tested in the presence of the other basal transcription factors, only reactions performed with TFIIH were stimulated by the presence of promoter, therefore suggesting that MO15 requires other TFIIH components to carry out this reaction efficiently.

\section{Evidence for Different Forms of TFIIH}

The existence of two or more MO15-containing complexes is apparent from the immunoprecipitation experiments.
We thus performed glycerol gradient shift experiments (Figure 4) using TFIIH (HAP, fraction 12) and either purified rabbit anti-TFIIB antibody (Ab-Control) or Ab-MO15. In the gradient performed with Ab-Control, transcription, CTD kinase, and CAK activity, as well as MO15, p62, p80, and p89, peaked in fractions 7 and 8 . No significant CTD kinase or CAK activity could be detected elsewhere on the gradient, suggesting that these two activities are associated with TFIIH.

In the second gradient, Ab-MO15 displaces the MO15 antigen along with the CTD kinase and the CAK activities (from fractions 7-8 to fractions 8-14), thus demonstrating the presence of at least two qualitatively different complexes, one of which is shifted by the antibody, while the other(s) sediments in a similar manner as TFIIH on the $\mathrm{Ab}$-Control gradient (compare the band intensity levels of the four polypeptides in fractions 7 and 8 of the $A b-C o n t r o l$ gradient and of the same fractions of the TFIIH plus AbMO15 gradient and also the difference in stoichiometry between the polypeptides present in fractions 7 and 11 in TFIIH plus Ab-MO15, respectively, shown in Figure 4). Interestingly, the Ab-MO15-induced shift of the MO15associated kinase activities compromised the levels of transcription by approximately 10 -fold compared with that recovered from the gradient performed with the Ab-Control (Figure 4). It is improbable that this reduction in transcription activity is due to an inhibitor present in the antibody fraction since, prior to our performing the gradient sedimentations, similar titers of antibody demonstrated no inhibitory effect on any of the enzymatic functions associated with TFIIH. Therefore, the diminished transcription activity is most likely due to the disruption of the fully active TFIIH. These results also show that appoximately $30 \%$ of the total p80/ERCC2 present in TFIIH was also shifted with the human MO15 and its associated activities, strongly suggesting an association between both polypeptides in the shifted complexes.

\section{Phosphorylation of RNA Pol II and Transcription Activity}

To establish further a relationship between the ability of MO15 to phosphorylate the CTD of the large subunit of RNA pol II and transcription activity, we tested a series of different TFIIH-derived fractions (Figure 5A). The AbControl flowthrough (FT) fraction contained each of the TFIIH subunits present in the load in addition to MO15 (Western blot; Figure 5A, lanes 1 and 2), whereas the FT of the other immunoaffinity columns (Ab-ERCC3, AbERCC2, and Ab-MO15) contained little or none of these polypeptides (lanes 3-5). The Ab-ERCC3 and Ab-ERCC2 eluate fractions (see Experimental Procedures) contained p89, p80, and p62 (Figure 5A, lane 6) in addition to p44 and p34 (data not shown) and to p80 and M015 (lane 7). respectively.

All the fractions that contained MO15 phosphorylated the ctd4 oligopeptide (Figure 5A, lanes 1, 2, and 7). On the other hand, only the FT of Ab-Control, as well as the load, were able to phosphorylate the CTD of the large subunit of RNA pol Il under transcription conditions (Figure $5 A$, lanes 2 and 1, respectively). Neither the MO15 nor 
A
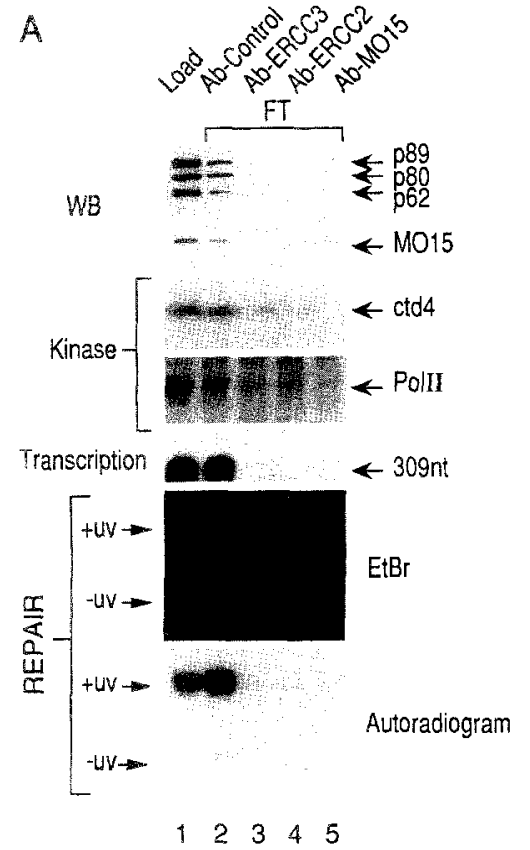

$B$

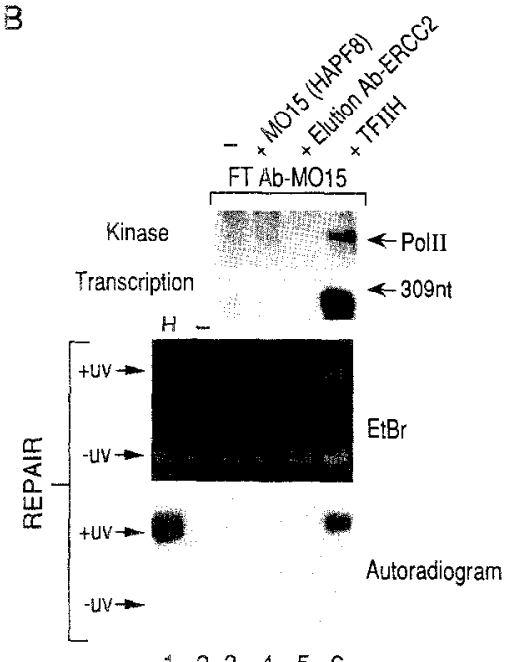

123456

Figure 5. MOY5 Depletion Abrogates TFIIH Transcription, Kinase, and Repair Activities

Heparin-5PW (500 $\mu$ l) (fraction 12; load) (lane 1) was applied on protein A-Sepharose that contained either Ab-Control, Ab-ERCC3, Ab-ERCC2, or Ab-MO15 antibodies as described in the legend of Figure 1. The FT fractions and the eluates (as indicated at the top of the panel), either alone $(A)$ or in complementation experiments $(B)$, were tested in kinase assays using either ctd 4 or RNA pol II, for TFIIH-dependent iranscription activity, in in vitro DNA repair assays, and also by immunoblotting (shown as WB). TFIIH was HAP fraction $12(3 \mu \mathrm{l}) ; \mathrm{H}$ and minus refer to reactions performed with HeLa and GM2552A (ERCC3 ${ }^{-}$) WCEs, respectively. $\mathrm{EtBr}$, ethidium bromide.

the Ab-ERCC2 eluate fractions were capable of phosphorylating RNA pol II despite the fact that both possessed MO15 and a CTD (peptide) kinase activity.

Addition of MO15 or the Ab-ERCC2 eluate (which contains p80 and MO15) to the FT Ab-MO15 fraction had no restoring effect on RNA pol II phosphorylation (Figure 5B, lanes 4 and 5). The Ab-ERCC3 eluate (which contains p89,

\begin{tabular}{|c|c|c|}
\hline injected Antiserum & $\begin{array}{l}\text { Percent Femaining } \\
\text { Transcription }\end{array}$ & $\begin{array}{l}\text { Percent Remaining } \\
\text { NEA }^{\text {a }}\end{array}$ \\
\hline $\mathrm{Ab}-\mathrm{MO} 15$ & 57 & 50 \\
\hline $\mathrm{Ab}-\mathrm{ERCC} 3^{\mathrm{b}}$ & 52 & 57 \\
\hline$A b-E R C C 1^{b}$ & 100 & 3 \\
\hline Nonimmune serum & 93 & 98 \\
\hline
\end{tabular}

a Derived from grain countings of nuclei of injected cells, compared with the grains above nuclei from noninjected neighboring fibroblasts. ${ }^{\circ}$ See van Vuuren et al. (1994).

p80, p62, p44, and p34) was also ineffective in restoring this activity (data not shown). None of the latter fractions were active in our transcription system, either alone or in combination. Only when TFIIH or FT Ab-Control are added back to the FT Ab-MO15 can phosphorylation of RNA po II and transcription be restored (data not shown; Figure $5 B$, lane 6). Our inability to reconstitute TFIIH activity could be due to some irreversible denaturation of the complex during the various immunoaffinity wash steps. From the present data, we conclude that the CTD kinase activity associated with MO15 is not sufficient efficiently to phosphorylate the CTD of RNA pol II, to phosphorylate transcription, or both. Phosphorylation of RNA polymerase and maximal transcription require the presence of $\mathrm{MO} 15$ in addition to other, if not all, the TFIIH subunits.

\section{Involvement of MO15 in DNA Repair and Transcription}

The previous fractions first were tested for their ability to restore the DNA repair in a XPB/ERCC3 repair-deficient cell extract. Only the FT Ab-Control restored the DNA repair activity whereas the FT Ab-ERCC3, FT Ab-ERCC2, and FT Ab-MO15 were inactive (Figure 5A). Addition of TFIIH as well as recombinant ERCC3 (van Vuuren et al. 1994) to the ERCC3-deficient WCE combined with the FT Ab-MO15 (Figure 5B, lanes 1 and 6; data not shown) restored the DNA repair activity. However, if M015 alone or MO15 associated with ERCC2 was added to the NER extract, no repair of the damaged DNA was observed (Figure $5 \mathrm{~B}$, lanes 4 and 5 ). All together, these results suggest that the absence of NER activity in the FT of the Ab-MO15 depleted fraction is not directly due to the removal of MO15 kinase itself, but rather to the overall depletion of ERCC3 included in a complex that also contains both MO15 and ERCC2, namely TFIIH.

In a second set of experiments, we showed that microinjection of Ab-MO15 into the cytoplasm of normal human fibroblasts (Vermeulen et al., 1994) results in a marked decrease in both transcription (as determined by incorporation of [ $\left.{ }^{3} \mathrm{H}\right]$ uridine) and NER (as determined by the level of ultraviolet [UV]-induced [ $\left.{ }^{3} \mathrm{H}\right]$ thymidine incorporation; Figure 6; Table 2). Microinjection of antibodies against ERCC1, a polypeptide exclusively devoted to the repair reaction, had no effect on RNA synthesis (Table 2). We atribute the remaining residual activity to incomplete access of the antibody to the MO15 protein or an insufficient titer of the serum, as was also seen with XPB/ERCC3 

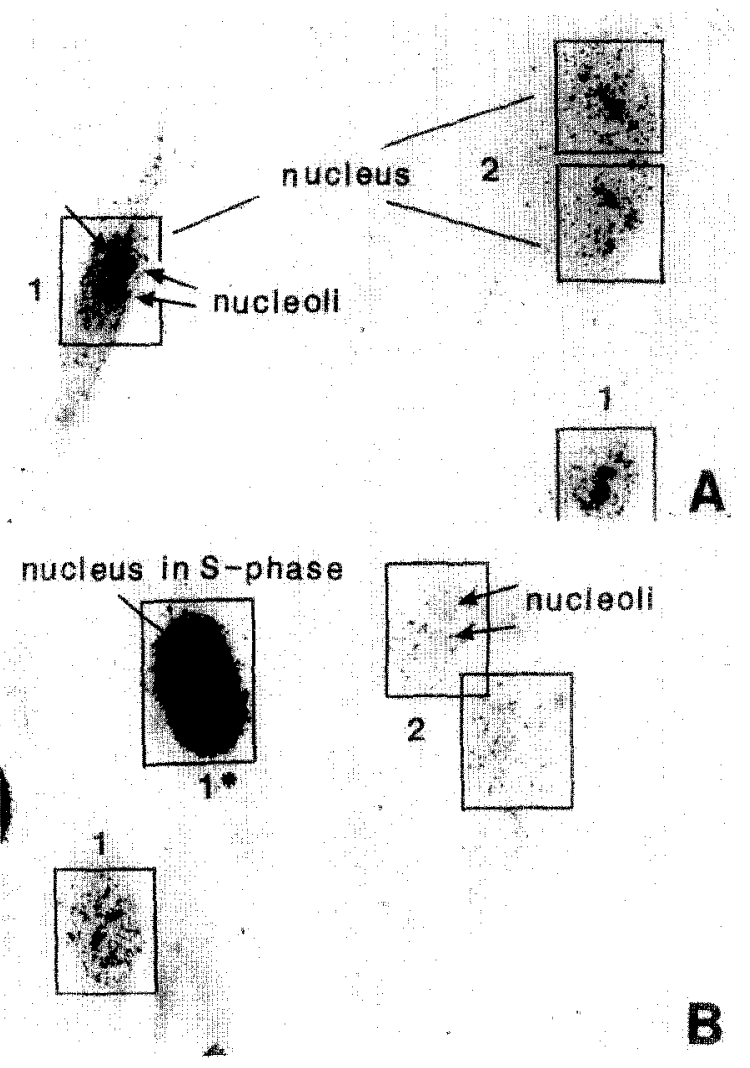

B

Figure 6. Effect of Microinjection of MO15 Antibodies on Transcription and NER of Normal Cells

Micrographs demonstrating the inhibition of general transcription (A) and DNA repair $(B)$ in vivo after injection of Ab-MO15 in the cytoplasm of normal human fibroblasts (C5RO). RNA synthesis is assayed by a $1 \mathrm{hr}$ pulse labeling with [ $\left.{ }^{3} \mathrm{H}\right]$ uridine and visualized by in situ autoradiography. NER synthesis was measured by incorporation of [3H]thymidine over a period of $2 \mathrm{hr}$ immediately following UV exposure $\left(15 \mathrm{~J} / \mathrm{m}^{2}\right)$. The heavily labeled nucleus is from a cell in $\mathrm{S}$ phase during $\left.\left.\right|^{3} \mathrm{H}\right]$ thymidine incubation. Note the morphological changes in the nuclei (in particular the disappearance of the nucleoli) in the injected dikaryon. The injected cells are indicated with an arrow. Only multinuclear cells were used for injection (indicated as 2), generated by cell fusion using inactivated Sendai virus, and were compared with the neighboring noninjected cells (indicated as 1).

antiserum. Although the microinjection of Ab-MO15 inhibits DNA repair and transcription, we cannot presently rule out that the effect of MO15 antibodies is indirect via the activation of some other CDK required for these two processes.

\section{Discussion}

Research on the transcription of protein-coding genes has now reached the stage at which the main factors that constitute the basal transcription machinery have been identified. Very little is known concerning the catalytic steps underlying the formation of the initiation complex and its conversion to an elongation complex in order to begin RNA synthesis.

We report here that the previously cloned human MO15 protein kinase, the activity of which was measured by the phosphorylation of $\mathrm{p} 33^{\mathrm{cdk} 2}$ and by the CAK assay, is associ- ated with TFIIH and is responsible for its CTD kinase activity. Furthermore, when this CTD kinase activity is dissociated from TFIIH, it continues to copurify with MO15, suggesting that this protein kinase is the catalytic subunit of the TFIIH-associated kinase. Surprisingly, following the partial dissociation of TFIIH with $0.05 \%$ sarcosyl followed by glycerol gradient sedimentation, the kinase activities and MO15 migrated to a position on the gradient that corresponded to the $94 \mathrm{kDa}$ size marker, far from the position one would expect for a $40 \mathrm{kDa}$ polypeptide monomer (data not shown). That TFIIH possesses CAK activity, whereas the recombinant MO15 requires the presence of cyclin $\mathrm{H}$ for CAK (Fisher and Morgan, 1994; Mäkelä et al., 1994), implies that TFIIH is also complexed with cyclin $\mathrm{H}$. In fact, when immunoprecipitations of a partially purified TFIIH fraction with $\mathrm{Ab}-\mathrm{ERCC} 2$ under medium high salt conditions $(0.5 \mathrm{M} \mathrm{KCl})$ are performed, a triplet consisting of MO15, p34, and p32, in addition to the known TFIIH subunits, was visualized on silver-stained polyacrylamide gels (data not shown). Our microsequencing data (HWTFSS EEQLAR and TADDFLNR) confirms the presence of the cyclin $\mathrm{H}$ regulatory partner of MO15 in a highly purified TFIIH fraction (R. R. and J.-M. E., unpublished data).

We did not find any homology between the CTD and the $T$ loop sequence of $p 33^{c d k 2}$ and $p 34^{c o c 2}$. Thus, the fact that TFIIH is capable of phosphorylating very different substrate sites is somewhat perplexing, the CTD, however, being a more typical substrate for a CDK.

\section{M015 and Transcription}

Although we could not present direct evidence for a functional role of MO15 and its kinase activity in the transcription reaction, the following facts strongly suggest that MO15 plays a role in this step of gene expression. First, MO15 is associated with the TFIIH transcription factor. Second, microinjection experiments using Ab-MO15 reduced in vivo RNA synthesis, thus adding to previous results that have shown that an antibody directed toward the p62 TFIIH subunit results in an inhibition of both RNA pol II phosphorylation and transcription activity (Lu et al., 1992; Fischer et al., 1992). Third, Ab-MO15 depletes an activity necessary for RNA pol II phosphorylation and transcription. The fact that MO15 alone is not sufficient to restore both activities suggests that phosphorylation as well as RNA synthesis likely requires certain other key TFIIH subunits.

\section{is TFIIH Involved in Cell Cycle Regulation?}

It is intriguing that a protein kinase involved in the regulation of the cell cycle is associated with a basal transcription-repair factor. The most trivial explanation would be that the cell uses the same essentially unregulated kinase for two independent processes. The CAK activity of MO15 has been shown to remain constant during the mammalian cell cycle (Tassan et al., 1994). Thus, it is possible that it is only the availability of the substrate (that is, $\mathrm{p} 34^{\mathrm{cdc} 2}$ with a bound cyclin) that regulates the activity of MO15 as the cdc2-activating kinase. Similarly the CTD kinase of MO15 associated with TFIIH may only depend on a transcription context bringing kinase and substrate into close proximity. 
Thus, if the MO15 kinase activity remains constant under different physiological conditions, the cell can afford to use the same kinase for two functions without having these interfere with each other.

Alternatively, M015 could respond to an unidentified cellular signal to relay it both to the cell cycle and transcription apparatuses. The links among a cell cycle kinase, basal transcription, and DNA repair revealed by the present work set the scene for an interesting scenario. DNA darnage induces cell cycle arrest. The checkpoints of this cellular response (reviewed by Murray, 1993) serve to provide DNA repair systems the time to eliminate lesions in DNA. For example, MO15 may respond to DNA-damaging agents through its interaction with the p80/ERCC2 helicase, a subunit of TFIIH. However, it is currently unknown which process senses DNA injury first and generates the primary trigger that eventually results in cell cycle arrest. Transcription constitutes a process that continuously subjects large, vital parts of the genome to a rigorous test for intactness since it is effectively blocked by lesions in the template. Thus, the RNA pol II machinery indirectly performs a cell cycle-independent surveillance for genome integrity. The identification of a cell cycle kinase as an integral component of the basal transcription apparatus may provide a link between blocked transcription by DNA lesions and cell cycle control. Thus, TFIlH-associated MO15 could initiate the signaling cascade via activation of various CDKs that lead to cell cycle arrest in $\mathrm{G} 1, \mathrm{~S}$, or $\mathrm{G} 2$ when transcription is hampered. Alternatively (or additionally), the kinase activity may be required for recruiting TFIIH from the transcription mode into the repair configuration or vice versa.

\section{Toward Several Forms of Specialized TFIIH Complexes}

In the light of glycerol gradient shift and immunoprecipitation experiments (this study; see also Schaeffer et al., 1994), it seems that there are forms of TFIIH complexes that differ qualitatively, quantitatively, or both in their polypeptide composition. Moreover, a TFllH-free form of MO15, likely associated with its regulatory subunits, can be partially dissociated from TFIIH with high concentrations of ammonium sulfate (Gérard et al., 1991; Schaeffer et al., 1994). Considerable discrepancy in the published molecular mass of CAK containing MO15 supports this possibility. In human cells, native molecular masses of $60-120 \mathrm{kDa}$ (Tassan et al., 1994), $180 \mathrm{kDa}$ (Fisher and Morgan, 1994), and $300-400 \mathrm{kDa}$ (Wu et al., 1994) were reported. Poon et al. (1993) and Fesquet et al. (1993) showed two peaks (corresponding to molecular masses of 80 and 180-220 $\mathrm{kDa}$ ) of CAK activity in X. laevis egg extract. It is not clear whether these differences reflect different functional entities in vivo, but it is possible that the $80 \mathrm{kDa}$ complex corresponds to MO15-cyclin $\mathrm{H}$, the $180 \mathrm{kDa}$ complex to MO15-cyclin H-ERCC2, and the 300-400 kDa complex to TFIH. All these forms strongly suggest a heterogeneity of the MO15-TFIIH complex reminiscent of the suggested factor b repairosome that includes three different functional entities (Svejstrup et al., 1994). Feaver et al. (1994 [this issue of Cell]) show that KIN28, the yeast homolog of MO15 (47\% identity; $68 \%$ similarity) is aiso part of yeast factor $b$. This demonstrates once again the functional and structural equivalence of both the yeast and the human TFIIH, which share Rad25/ERCC3, Rad3/ERCC2, Tfb1/ p62, SSL1/p44, and now KIN28/MO15 subunits. The heterogeneity in the composition of TFIIH (see Figure 2) and factor b (Svejstrup et al., 1994) suggests that the various functions of TFIIH in transcription, repair, and possibly in cell cycle control could be associated with different TFIIH complexes.

\section{Experimental Procedures}

\section{Phosphorylation Reactions}

Kinase assays using the synthetic oligopeptides were as in Cisek and Corden (1991), while GST-cdk2 phosphorylation and CAK activity were performed according to Ponn et al. (1993).

The phosphorylation of RNA pol II was performed essentially as described elsewhere (Serizawa et al., 1992). In brief, preinitiation complexes were formed as in a typical runoff transcription reaction in a $20 \mu l$ volume using a reconstituted in vitro system (Humbert et al., 1994). Following an incubation of the complexes for $15 \mathrm{~min}$ at $25^{\circ} \mathrm{C}$ the reactions were completed to $25 \mu \mathrm{l}$ by adding radioinert $G T P, C T P$, UTP $(0.20 \mathrm{mM}$ final concentration), and ATP $(0.02 \mathrm{mM}$ final concentration) in addition to $2 \mu \mathrm{Ci}$ of $\left[\gamma^{32} \mathrm{P}\right] \mathrm{ATP}(7000 \mathrm{Ci} / \mathrm{mmol})$. After $45 \mathrm{~min}$ at $25^{\circ} \mathrm{C}$, the incubation mixture was subjected to SDS-polyacrylamide gel electrophoresis (SDS-PAGE) on a $9 \%$ polyacrylamide gel. The gel was dried and autoradiographed.

\section{Immunological Methods}

The polyclonal anti-MO15 and the monocional antibodies against the various TFIIH subunits (Tassan et al., 1994; Humbert et al., 1994; Schaefier et al., 1994) were cross-linked to protein A-Sepharose. For the immunoaffinity columns, $200 \mu$ l of a $50 \%$ slurry (antibody-bound protein A-Sepharose) was incubated with $500 \mu$ l of a partially purified TFIIH fraction (heparin-5PW) for $1 \mathrm{hr}$ at $4^{\circ} \mathrm{C}$. The various steps were as described previously (Schaeffer et al., 1994). In brief, Ab-ERCC3 and Ab-ERCC2 columns were extensively washed with $0.5 \mathrm{M}, 1 \mathrm{M}$, and $2 \mathrm{M} \mathrm{KCl}$ and reequilibrated to $0.05 \mathrm{M} \mathrm{KCl}$ for elution using the synthetic peptides ( $2 \mathrm{mg} / \mathrm{ml}$ final concentration) ASRRFGTMSSMS. GADDTSETD for Ab-ERCC3 and LESEETLKRIEQIAQQL for Ab. ERCC2. To remove the peptide, we dialyzed the resulting eluates against $50 \mathrm{mM}$ Tris- $\mathrm{HCl}$ (pH 7.6), $0.1 \mathrm{mM}$ EDTA, $0.50 \mathrm{mM}$ DTT, 50 $\mathrm{mM} \mathrm{KCl}, 10 \%$ glycerol (v/v).

For immunoprecipitations, the fraction to be tested was diluted 10 fold in buffer A (100 mM NaCl, $20 \mathrm{mM}$ Tris-HCl $\mathrm{pH}$ 8), $1 \mathrm{mM}$ DTT, $0.1 \%$ EDTA), and $10 \mu \mathrm{l}$ of antibody beads were added. After $1 \mathrm{hr}$ of shaking at $4^{\circ} \mathrm{C}$, the beads were washed four times in buffer $A$ and once in kinase buffer. An aliquot was used for kinase assays and the rest was taken up in SDS sample buffer.

\section{DNA Repair Synthesis}

Plasmids pUC309 and PET3a (Novagen) were grown in $E$. coli strain $\mathrm{DH} 5 \alpha$, and plasmid DNA was isolated by alkaline lysis. The plasmid DET3a was UV irradiated $\left(450 \mathrm{~J} / \mathrm{m}^{2}\right)$ as described (Wood et al., 1988) Both plasmids were treated with $E$. coli Nth protein (provided by $R$. Wood). Standard $50 \mu$ i reaction mixtures contained $250 \mathrm{ng}$ of nonirradiated and irradiated DNA in addition to $80 \mathrm{mg}$ of protein HeLa or GM2552A $\left(E R \mathrm{CC}^{-}\right)$WCE. Reactions were incubated at $30^{\circ} \mathrm{C}$ for $3 \mathrm{hr}$. Plasmid DNA was purified from the reaction mixtures, linearized with BamHI. and electrophoresed overnight on a $1 \%$ agarose gel containing 0.5 $\mathrm{mg} / \mathrm{ml}$ ethidium bromide. The DNA was visualized, and the gel was dried and autoradiographed.

\section{Other Methods}

Protein purification of TFIIH and microsequencing of the polypeptides were performed as previously described (Fischer etal., 1992). Glycerol gradients and antibody shifts were as in Schaeffer al. (1994). 


\section{Acknowledgments}

Correspondence should be addressed to J.-M. E. We thank T. Hunt for advice and for the recombinant cyclin A, L. Tsal for the GST-cdk2 construct, J. Corden for the mutant CTD peptides, and M. Dahmus for purified RNA pol II. We are grateful to R. Kornberg, to W. Feaver and J. Svejstrup, and to J. Corden for the communication of unpublished data and for fruitful discussions. We thank $A$. Fery for technical assistance and A. Staub for the protein microsequencing. We are thankful to $\mathrm{V}$. Moncollin and $\mathrm{S}$. Humbert for fruitful discussion and particularly to $P$. Chambon for his unfailing support and guidance. R. R. was supported by a fellowship from the Association pour la Recherche sur le Cancer and J. P. A. by a European Molecular Biology Organization long-term fellowship. This work was supported by grants from the Institut National de la Santé et de la Recherche Médicale, the Centre National de la Recherche Scientifique, the Ministère de la Recherche et de l'Enseignement Supérieur, the Centre Hospitailer Regional de Strasbourg, the Association pour la Recherche sur le Cancer, the Swiss Cancer League, and the Dutch Cancer Society (EUR-9020, 92-118)

Received November 3, 1994; revised November 15, 1994.

\section{References}

Bootsma, D., and Hoeijmakers, J. H. J. (1993). Engagement with transcription. Nature 363, 114-115.

Chalut, C., Moncollin, V., and Egly, J.-M. (1994). Transcription by RNA polymerase II: a process linked to DNA repair. Bioessays $16,651-$ 655.

Cisek, L. J., and Corden, J. L. (1991). Purification of protein kinases that phosphorylate the repetitive carboxy-terminal domain of eukaryotic RNA polymerase II. Meth. Enzymol. 200, 301-325.

Conaway, R. C., and Conaway, J. W. (1989). An RNA polymerase II transcription factor has an associated DNA-dependent ATPase (dATPase) activity strongly stimulated by the TATA region of promoters. Proc. Natl. Acad. Sci. USA 86, 7356-7360.

Dahmus, M. E. (1994). On the role of the C-terminal domain of RNA polymerase II in the transcription of pre-mRNA. In Transcription, Mechanisms, and Regulation, R. C. Conaway and J. W. Conaway, eds. (New York: Raven Press), pp. 243-262.

Drapkin, R., Reardon, J. T., Ansari, A., Huang, J.-C., Zawel, L., Ahn, K., Sancar, A., and Reinberg, D. (1994). Dual role of TFIIH in DNA repair and in transcription by RNA polymerase II. Nature 368, 769772.

Feaver, W. J., Gileadi, O., Li, Y., and Kornberg, R. D. (1991). CTD kinase associated with yeast RNA polymerase $\|$ initiation factor $b$. Cell $67,1223-1230$.

Feaver, W. J., Svejstrup, J. Q., Bardwell, L., Bardwell, A. J., Buratowski, S., Gulyas, K. D., Donahue, T. F., Friedberg, E. C., and Kornberg, R. D. (1993). Dual roles of a multiprotein complex from $S$. cerevisiae in transcription and DNA repair. Cell 75, 1379-1387.

Feaver, W. J., Svejstrup, J. Q., Henry, N. L., and Kornberg, R. D. (1994). Relationship of CDK-activating kinase and RNA polymerase II CTD kinase TFIIH/TFIIK. Cell 79, this issue.

Fesquet, D., Labbé, J.-C., Derancourt, J., Capony, J.-P., Galas, S., Girard, F., Lorca, T., Shuttleworth, J., Dorée, M., and Cavadore, J.-C. (1993). The MO15 gene encodes the catalytic subunit of a protein kinase that activates cdc2 and other cyclin dependent kinases (CDKs) through phosphorylation of Thr161 and its homologues. EMBO J. 12 , 3111-3121.

Fischer, L., Gérard, M., Chalut, C., Lutz, Y., Humbert, S., Kanno, M., Chambon, P., and Egly, J.-M. (1992). Cloning of the 62-kilodalton component of basic transcription factor BTF2. Science $257,1392-$ 1395.

Fisher, R. P., and Morgan, D. O. (1994). A novel cyclin associates with MO15/CDK7 to form the cdk-activating kinase. Cel! 78, 713-724. Gérard, M., Fischer, L., Moncoilin, V., Chipoulet, M., Chambon, P., and Egly, J.M. (1991). Purification and interaction properties of the human RNA polymerase $B$ general transcription factor BTF2. J. Sioi. Chem. 266, 20940-20945.

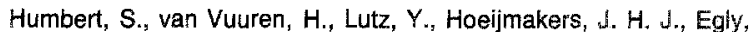
J.-M., and Moncollin, V. (1994). p44 and p34 subunits of the BTF2/ TFIIH transcription factor have homologies with SSL1, a yeast protein involved in DNA repair. EMBO J. 13, 2393-2398.

Lu, H., Zawel, L., Fisher, L., Egly, J.-M., and Reinberg, D. (1992). Human general transcription factor IIH phosphorylates the C-terminal domain of RNA polymerase II. Nature 358, 641-645.

Ma, L., Westbroek, A., Jochemsen, A. G., Weeda, G., Bosch, A., Boot sma, D., Hoeijmakers, J. H. J., and van der Eb, A. J. (1994). Mutational analysis of ERCC3, which is involved in DNA repair and transcription initiation: identification of domains essential for the DNA repair function. Mol. Cell. Biol. 14, 4126-4134

Mäkelä, T. P., Tassan, J.-P., Nigg, E. A., Frutiger, S., Hughes, G. J., and Weinberg, R. A. (1994). A cyclin associated with the CDKactivating kinase MO15. Nature 371, 254-257.

Murray, A. W. (1993). Creative blocks: cell cycle checkpoints and feed back controls. Nature 359, 599-604.

Poon, R. Y. C., Yamashita, K., Adamczewski, J. P., Hunt, T., and Shuttleworth, J. (1993). The cdc2-related protein p40mo15 is the catalytic subunit of a protein kinase that can activale $\rho 33^{\text {ceks }}$ and $p 34^{\text {cds2 }}$. EMBO J. 12, 3123-3132.

Roy, R., Schaeffer, L., Humbert, S., Vermeulen, W., Weeda, G., and Egly, J.-M. (1994). The DNA dependent activity associated with the class II basic transcription factor BTF2/TFIIH. J. Biol. Chem. 13,98269832

Schaeffer, L., Roy, R., Humbert, S., Moncollin, V., Vermeulen, W., Hoeijmakers, J. H. J., Chambon, P., and Egly, J.-M. (1993). DNA repair hellcase: a component of BTF2 (TFIIH) basic transcription factor. Science $260,58-63$.

Schaeffer, L., Moncollin, V., Roy, R., Staub, A., Mezzina, V., Sarazin, A., Weeda, G., Hoeijmakers, J. H. J., and Egly, J.M. (1994). The ERCC2/DNA repair protein is associated with the class II BTF2/TFIIH transcription iactor. EMBO J. 13, 2388-2392.

Serizawa, H., Conaway, R. C., and Conaway, J. W. (1992). A carboxy terminal-domain kinase associated with RNA polymerase II transcription factor $d$ from rat liver. Proc. Natl. Acad. Sci. USA 89, 7476-7480. Serizawa, H., Conaway, R. C., and Conaway, J. W. (1993). Multifunctional RNA polymerase II initiation factor d from rat liver: relationship between carboxy-terminal kinase ATPase and DNA helicase activities. J. Biol. Chem. 268, 17300-17308.

Svejstrup, J. Q, Wang, Z., Feaver, W. J., Wu, X, Donahue, T. F. Friedberg, E. C., and Kornberg, R. D. (1994). Different forms of RNA polymerase transcription factor TFIIH (TFIIH) for transcription and DNA repair: holo TFIIH and a nucleotide excision repairosome. Nature, in press.

Tassan, J.-P., Schultz, S. J., Bartek, J., and Nigg, E. A. (1994). Cell cycle analysis of the activity, subcellular localization and subunit composition of human CAK (cdk-activating kinase). J. Cell Biol. 127, 467478.

Usheva, A., Maldonado, E., Goldring, A., Lu, H., Houbavi, C., Reinberg, $D$., and Aloni, $Y$. (1992). Specific interaction between the nonphosphorylated form of RNA polymerase II and the TATA-binding protein. Cell 69, 871-881.

van Vuuren, A. J., Vermeulen, W., Ma, L., Weeda, G., Appeidoorn, E., Jaspers, N. G. J., van der Eb, A. J., Bootsma, D., Hoeijmakers, J. H. J., Humbert, S., Schaeffer, L., and Egly, J.-M. (1994). Correction of xermoderma pigmentosum repair defect by basal transcription factor BTF2 (TFIIH). EMBO J. 13, 1645-1653.

Vermeulen, W., Scott, R. J., Potger, S., Müller, H. J., Cole, J., Arlett, C. F., Kleijer, W. J., Bootsma, D., Hoeijmakers, J. H. J., and Weeda, G. (1994). Clinical heterogeneity with xeroderma pigmentosum mutations in the DNA repair and transcription gene ERCC3. Am. J. Hum Genet. 54, 191-200.

Wang, W., Carey, M., and Gralla, J. D. (1992). Polymerase II promoter activation: clased complex formation and ATP driven start site opening. Science $255,450-453$ 
MO15 in the Basal Transcription Factor TFIIH

$\$ 101$

Wang, Z,, Svejstrup, J. Q., Feaver, W. J., Wu, $X_{2}$, Kornberg, R. D., and Friedberg. E. C. (1994). Transcription factor $b$ (TFIIH) is required during nucleotide excision in yeast. Nature $368,74-76$.

Wood, F. D., Robins, P., and Lindahl, T. (1988). Complementation of the xeroderma pigmentosum DNA repair defect in cell-free extracts. Cell 53, 97-106.

Wu, L., Yee, A., Liu, L., Carbonaro-Hall, D., Venkatesan, N., Tolo, V. T., and Hall, F. L. (1994). Molecular cloning of the human CAK1 gene encoding a cyclin-dependent kinase-activating kinase. Oncogene 9, 2089-2096. 